\title{
EL DERECHO INDÍGENA COMO IMPULSOR DEL PLURALISMO JURÍDICO EN EL DERECHO MEXICANO
}

\author{
THE INDIGENOUS RIGHT AS AN AGENT OF LEGAL \\ PLURALISM IN MEXICAN LAW
}

\author{
Elisa Cruz Rueda*
}

\begin{abstract}
Argumentamos cómo pese a que existe un "mandato de ley” y una resolución de un órgano supremo, dentro de la jerarquía jurisdiccional mexicana, en la práctica de los funcionarios en regiones indígenas, esos mandatos se relativizan, trasmutando a criterios referenciales. Para ello introducimos el concepto de diáspora jurídica -concepto viajero- como una contribución a los análisis respecto del pluralismo jurídico situándolos frente a los conceptos centrales generados en el seno de la antropología jurídica y en el contexto de la relación entre el Estado mexicano y los pueblos indígenas, que marcan la conformación del campo jurídico, en donde uno de los centros generadores de Derecho es el Estado, pero existen otros como los pueblos indígenas.
\end{abstract}

Palabras claves: Conceptos viajeros, pluralismo jurídico, diáspora jurídica, Derecho mexicano y Derecho indígena.

We argue that despite the existence of a "law mandate" and a resolution of a supreme body, within the Mexican jurisdictional hierarchy, in the practice of officials in indigenous regions, these mandates are relativized, transmuting to referential criteria. To do this, we introduce the concept of legal diaspora -concept traveler- as a contribution to the analysis of legal pluralism placing them in front of the central concepts generated within legal anthropology and in the context of the relationship between the Mexican State and the peoples indigenous, which mark the conformation of the legal field, where one of the generating centers of law is the State, but there are others such as indigenous peoples.

Key words: Traveling concepts, Legal pluralism, Legal Diaspora, Mexican law and indigenous law.

\section{Introducción}

El trabajo se desarrolla en tres partes y reflexiones finales: (I) La diáspora jurídica como concepto viajero para explicar las dinámicas y procesos en la construcción del Derecho mexicano; (II) Entre la norma jurídica y los criterios de actuación de las autoridades y operadores de la justicia positivista; (III) La aplicación e interpretación de la norma: entre el pluralismo o la hegemonía del campo jurídico y Reflexiones finales.

En la primera parte se abordan los conceptos centrales de la antropología jurídica, especialmente el de pluralismo jurídico, utilizado para entender el fenómeno de generación de normas a la par, en paralelo o en relación estrecha (imbricación) con la actividad del Estado. En conjunto con este, y para comprender el pluralismo al interior del derecho mexicano, se hace uso de un concepto acuñado en las Ciencias Sociales para dar cuenta de las grandes migraciones y éxodos humanos: diáspora como concepto viajero de acuerdo con Bal (2006).
En la segunda parte y para ilustrar el fenómeno de "diáspora jurídica" al interior del Derecho mexicano, se analiza el protocolo de actuación acerca de indígenas, así como el criterio de la Suprema Corte de Justicia de la Nación (SCJN 2014) respecto de la interpretación del artículo $1^{\circ}$ de la Constitución Política de los Estados Unidos Mexicanos (CPEUM) por la aplicación de los Tratados Internacionales en materia de Derechos Humanos.

En la tercera parte se analizan casos de uso contestatario del Derecho estatal que detonan la diáspora jurídica por parte de las comunidades indígenas y sus organizaciones, frente a instituciones del Estado mexicano, para la reivindicación de sus derechos colectivos, en tres ámbitos: en la elección de sus autoridades tradicionales, en la separación de comuneros y en la regulación de las dinámicas sociales internas ${ }^{1}$. Para terminar con las reflexiones.

El argumento se desarrolla en torno al hecho de la existencia de un "mandato de ley" y una resolución de un órgano supremo -dentro de la jerarquía jurisdiccional mexicana-, pero en la práctica de los

* Universidad Autónoma de Chiapas, Escuela de Gestión y Autodesarrollo Indígena, Chiapas, México. Correo electrónico: elisacruzrueda@hotmail.com 
funcionarios en regiones indígenas, esos mandatos se relativizan, transmutando a criterios únicamente referenciales. Es decir, el Derecho mexicano no es homogéneo ni es una unidad llana o lineal, más bien, es un crisol de complejidades en criterios y normatividades, usos del derecho y su aplicación tanto por usuarios como por autoridades u operadores de la justicia. En determinados momentos, estas complejidades se encuentran aisladas entre sí y, en otros, se observa el intento, justamente por parte de la Suprema Corte de Justicia de la Nación (SCJN), de guardar la unidad del Derecho dictado por el Estado. Indudablemente esta perspectiva de análisis tiene sus cimientos en la antropología jurídica mexicana, que observa más allá de la letra de la norma y se interesa por los procesos de construcción del Derecho y cómo influyen en ellos los usos del poder.

\section{La diáspora jurídica como concepto viajero para explicar las dinámicas y procesos en la construcción del Derecho mexicano}

Ha sido abordado por muchos autores y autoras (Cruz 2014, Sieder y Sierra 2011; Sierra 2002; Chenaut y Sierra 1995) los últimos avances -génesis y desarrollo-del pluralismo jurídico (Santos 1991) como una de las bases teóricas fundamentales en el debate de la Antropología Jurídica sobre todo mexicana (Stavenhagen 1982). Por ello, en este apartado daremos por establecido ese debate y por aceptado el concepto de pluralismo jurídico como la coexistencia de sistemas jurídicos diversos por ejemplo: el sistema positivo mexicano y el sistema jurídico indígena, para enfocarnos en la explicación del uso del término de diáspora jurídica, que como lo mencionamos en la introducción reconocemos que tiene un origen y uso muy concreto y específico para hacer referencia a ciertos procesos de movimiento humano, migración e inmigración en el mundo.

Por lo anterior y antes de exponer el concepto de diáspora es importante agregar que al hacer una revisión de la literatura que se refiere justamente a la relación del Derecho positivo con el Derecho indígena (y este como expresión del pluralismo jurídico), la interlegalidad y los usos de poder, podemos apreciar que: 1 . Los estudios toman como eje central de referencia al Derecho positivo y desde ese lugar observan el "comportamiento" del Derecho indígena. 2. Los estudios que intentan tomar como eje central al Derecho indígena fracasan porque siempre lo hacen en su relación y comparación con los elementos del Derecho mexicano, resultando mostrar no tanto el Derecho indígena como propio sino las influencias y efectos del Derecho positivo en el Derecho indígena/nativo/originario por ejemplo. 3. Debido a la reivindicación indígena y de sus pueblos por más de veinte años, los estudios del Derecho indígena como eje central de análisis sin tomar como referencia central al Derecho positivo, son prácticamente inexistentes. Por ejemplo, en el Derecho O'dam: ¿cómo funcionan los curanderos como abogados y su contrafuerza, la brujería, en la dimensión de los sueños para resolver conflictos y esto cómo se muestra en la dimensión de la realidad material ${ }^{2}$.

Con el concepto de diáspora jurídica se intenta abonar en el estudio del pluralismo jurídico marcando la necesidad de hacerlo multilineal y mostrarlo en todo su dinamismo intentando que el análisis sea en doble vía (Derecho positivo-Derecho indígenaDerecho positivo) y no solo desde el Derecho positivo hacia el Derecho indígena, mostrando que este obliga a aquel "a moverse", detonando las diásporas al interior del Derecho mexicano.

Nos basamos en el planteamiento de conceptos viajeros que ha desarrollado Bal (2006), quien los define como "herramientas de la intersubjetividad" que no solo nombran sino además "distorsionan, desestabilizan y deforman", es decir, si los conceptos sirven para comunicar intersubjetividades, cuando viajan de una disciplina a otra se resignifican de acuerdo con quien los traslada y sus fines, y en doble vía también pueden ser reapropiados, dinamizados y convertidos en instrumentos de otros sujetos. En ese momento escapan del control de quien los trajo a las nuevas tierras o campos de estudio, por ello Bal señala que lo importante de los conceptos es "su fuerza operativa", es decir, su capacidad para explicar y significar hechos.

Es central la propuesta de Mieke Bal al considerar que los conceptos son flexibles y no inamovibles, que pueden surgir en un tiempo y espacio determinados geográfica y disciplinariamente, pero que no permanecen exclusivos, ya que su característica fundamental, sobre todo en las Ciencias Sociales y en las Humanidades, es justamente su carácter creativo y re-creativo, cuando son tomados y reapropiados por otras disciplinas por medio de la acción crítica y analítica del concepto mismo. Si bien la autora reconoce su carácter flexible, también reconoce la importancia de reconocer los orígenes y los usos 
históricos de los conceptos, pero sin quedarse ahí sino más bien poder entender nuevos usos.

Ante este viaje de conceptos la autora señala como indispensable la necesidad de no verlos como estáticos, pero a la vez subraya la importancia de establecer reglas comunes de "juego" o uso de los mismos, para lograr los diálogos interdisciplinares necesarísimos para comprender la realidad actual cada vez más vertiginosa y compleja.

\section{Diáspora jurídica}

En consonancia con la propuesta de Bal (2006) considero que el término de diáspora jurídica puede abonar justamente al diálogo interdisciplinar no solo entre la antropología y el derecho sino involucrar a otras disciplinas en el estudio del pluralismo jurídico.

Utilizo el término de diáspora jurídica para analizar cómo el Derecho mexicano que se quiere mostrar como único e indivisible sufre una suerte de dispersión en su aplicación e interpretación al momento en que se da el elemento subjetivo e intersubjetivo de operadores de la justicia y usuarios.

De esta manera la diáspora jurídica más que una metáfora es una herramienta para entender y estudiar el fenómeno del pluralismo jurídico, al interior del Derecho mexicano por efecto del uso del poder y del dinamismo de otros centros generadores de Derecho.

El concepto de pluralismo jurídico ha sido ampliamente definido y utilizado por la antropología jurídica en contextos de contacto cultural y de alteridad, es decir, para entender la existencia de otros centros generadores del Derecho y de la justicia. Sin embargo, no se ha utilizado suficientemente para comprender que, en la conformación y dinámica del Derecho positivo, también existe una suerte de pluralismo jurídico, lo que en parte se explica por la propia doctrina y tradición jurídica en la que está asentado el Derecho mexicano, caracterizadas por ser monistas y etnocéntricas, pero que ha dejado de lado el pluralismo generado por efecto del dinamismo y acción de otros centros generadores respecto del Derecho positivo mexicano.

Explicamos el concepto de diáspora jurídica al identificar y reconocer que existe un centro generador hegemónico (pero no el único) de normas y criterios de interpretación y aplicación (el Estado y como parte del poder público que este ejerce, el Poder Judicial) pero que, en situaciones, casos concretos y momentos históricos determinados, se relativizan para separarse de esa centralidad migrando a espacios de justicia que no son los que le dieron origen, que muchas veces son multiculturales y multiétnicos, y se mantienen ahí mientras no exista una fuerza centrípeta, por ejemplo, la acción o mandato de una autoridad central que las obligue a "alinearse" al orden establecido. Esto es más claro en los casos que manejamos en este trabajo, que justamente se dan en contextos multiculturales, en los que existe un entramado de relaciones entre el derecho positivo con formas y dinámicas locales de su aplicación, y entre los pueblos indígenas con el Estado mexicano, cuyo botón de muestra es la imbricación del derecho indígena con el derecho positivo.

Los espacios de justicia multiculturales y multiétnicos se ejemplifican con los casos que se abordan en el presente trabajo, y que tienen en común la historia de relación entre el Estado mexicano con los pueblos indígenas (en el caso de los wixaritari da cuenta el trabajo de Arcos 1998, Escalante 2010, Liffman 2012, Téllez Lozano, 2014. En el caso de los tzeltales y tsotsiles el trabajo Orantes García 2014 y 2007 y de los tsotsiles en Venustiano Carranza, Cruz y Elizondo 2016, Díaz de Salas 1995, González Esponda 1989, Renard 1998, Moreno 2014). Trabajos que revelan que tal relación está marcada por el colonialismo interno, el asimilacionismo, el paternalismo y el integracionismo.

En resumen, la conformación del campo jurídico comprende tanto al Estado mexicano como generador del derecho positivo como a otros centros generadores de derecho que provocan en él fenómenos de diáspora jurídica, como lo son las comunidades indígenas en su modalidad de ejidos, bienes comunales, agencias municipales y municipios, casos todos ellos que abordaremos más adelante.

\section{El campo jurídico y arenas de disputa}

El campo jurídico lo definimos parafraseando a Pierre Bourdieu (2011) y de acuerdo con Alicia Gutiérrez (en Bourdieu 2011), como un espacio social de acción definido por relaciones sociales determinadas entre clases, que constituyen una red de relaciones objetivas entre posiciones. Relaciones identificadas en la medida, en cuál es la contribución de cada clase en la construcción de la estructura social, y no solo por su importancia numérica. Es decir, la clase o cada clase "posee propiedades ligadas a las relaciones simbólicas que sostienen 
sus miembros entre sí y con las demás clases. Se trata de distinciones significantes, que expresan las diferencias de condición y de posición y que, de ese modo, tienden a la reduplicación simbólica de las diferencias de clase" (Gutiérrez 2011:12). Desde este planteamiento podemos ubicar distintos campos: social, económico, político, familiar.

De esta manera, uno de los conceptos centrales para entender el pluralismo jurídico es el de campo jurídico, en el que se identifican relaciones que pueden estar en acuerdo o confrontación dando lugar en este último caso a un conjunto de arenas de disputa, en las que se ponen en juego diversos aspectos culturales, políticos, culturales, sociales y económicos. Asimismo, es considerado como punto de partida para comprender las dinámicas internas de las comunidades indígenas y su relación con el Estado mexicano. La característica central del campo jurídico son las reglas que regulan a las relaciones y sobre todo las acciones que los individuos aplican para resolver esas disputas y que se pueden analizar a la luz de las normas jurídicas por implicar sanciones y obligaciones determinadas.

De igual forma, es por medio del campo jurídico que se puede apreciar el uso estratégico por parte de sujetos subalternos del Derecho del Estado para contestarlo, y que pueden ser indígenas y no indígenas y, con ello, lograr el reconocimiento de derechos antes negados aprovechando una diáspora jurídica o detonándola al interior del Derecho mexicano. Por ejemplo, derechos colectivos de los pueblos indígenas como es la justicia o el Derecho a la consulta, o bien cuando se plantea como objetivo el reconocimiento de una demanda (como es la tenencia de la tierra y el control territorial). Justamente estos temas claves: los usos del Derecho y del poder, han sido documentados por la antropología jurídica, mostrando que ese uso estratégico del Derecho es producto de la relación (sincrónica y diacrónica) que distintos sectores de la sociedad mexicana han tenido con el Estado, especialmente los pueblos indígenas, por sus procesos y dinámicas de confrontación interna.

Por la relación que el Estado mexicano ha establecido con los indígenas y sus pueblos, por el uso que hacen del Derecho estatal y por la exigencia de sus derechos -como el derecho a tener su propio derecho-, el campo jurídico solo puede ser entendido como parte de un contexto histórico y cultural específico, en una demarcación territorial concreta.
El concepto de poder dota de dinamismo al campo jurídico y detona la diáspora jurídica, ya que se presenta en todas las relaciones entre personas, grupos, instituciones y niveles legales, así como en sus acuerdos y desacuerdos, en sus encuentros y desencuentros. El poder, como Adams (1978) lo definió, es la capacidad para lograr que alguien haga lo que nosotros queremos, debido al control que tenemos acerca de aspectos culturalmente relevantes y significativos en una sociedad determinada.

\section{Lo agrario y lo municipal en la relación del Estado mexicano con los pueblos indígenas}

Los ejemplos que mostraremos más adelante se dan en el ámbito de lo agrario (lo rural, las normas respecto del uso de la tierra, la adscripción a un núcleo agrario, etc.). Por ello es importante considerar que el estudio del campo jurídico adquiere especial relevancia si se considera que la relación que el Estado mexicano ha establecido con las comunidades indígenas, por lo menos durante los siglos XIX y XX, ha pasado en gran medida por la imposición de normas y leyes, definidas especialmente desde la legislación federal, sobre todo, en lo que tiene que ver con la materia agraria y municipal. El espacio municipal como ámbito de administración político-territorial, pero sobre todo como nivel de gobierno, representa un espacio de control y de ejercicio de poder. La tierra, como fuente de riqueza fundamental y como expresión territorial de la delimitación del poder político del Estado, ha sido uno de los aspectos (junto con el municipio) en donde este ha ejercido control sobre la población rural, sobre todo de los campesinos y de los indígenas. De igual forma, mucho antes de la constitución del Estado mexicano -y una vez instaurado este-, los pueblos indígenas han sido afectados en la posesión y propiedad de sus tierras ${ }^{3}$.

Es en los últimos veinte años que la relación del Estado con los pueblos indígenas se ha transformado, lo que ha llevado al reconocimiento de ciertos derechos de los indígenas, sus comunidades y pueblos.

\section{Entre la norma jurídica y los criterios de actuación de las autoridades y operadores de la justicia positivista}

A la luz del Protocolo de actuación para quienes imparten justicia en casos que involucren derechos 
de personas, comunidades y pueblos indígenas, publicado por la Presidencia de la Suprema Corte de Justicia de la Nación (SCJN) en marzo de 2013 (y una segunda edición en el 2014), y de la Resolución emitida por el pleno de la SCJN (septiembre de 2013), concerniente a la aplicación de los tratados internacionales en materia de Derechos Humanos, se analizarán casos de uso del Derecho frente a instituciones del Estado mexicano por comunidades indígenas, para la reivindicación de sus derechos colectivos: en la elección de sus autoridades tradicionales, en la separación de comuneros y en la reglamentación interna.

Antes de exponer y analizar los casos, en los que daremos cuenta del pluralismo jurídico al interior del derecho mexicano y cómo se presenta la diáspora jurídica, explicaremos cómo la resolución de la SCJN respecto de la aplicación de los tratados internacionales a nivel interno o nacional es justamente un intento de los operadores del Derecho por mantener su naturaleza monista de unificación y homogeneidad, en oposición al pluralismo jurídico, que de facto se da en y para su implementación. Considero que la resolución de la SCJN (resultado de las sesión de 2 y 3 de septiembre de 2013), sobre la aplicación de los tratados internacionales en materia de Derechos Humanos (Cruz y Santana, 2013), muestra la actual etapa del multiculturalismo mexicano (Valladares et al., 2009).

\section{El bloque de constitucionalidad}

La discusión por parte del Poder Judicial de la Federación representado por la SCJN, sobre el reconocimiento y eventual adopción de un bloque de constitucionalidad, se caracterizó por los disentimientos entre dos posturas: se acepta el bloque de constitucionalidad, o solo se acepta la jerarquía constitucional de los tratados internacionales en materia de Derechos Humanos, siempre y cuando no traspasen los límites que la Constitución Federal establece. Disentimiento que muestra las tensiones y aparentes contradicciones del propio sistema jurídico, ya que, con antelación, el ministro presidente de la SCJN impulsó la publicación del Protocolo de Actuación para quienes imparten justicia en casos que involucren derechos de personas, comunidades y pueblos indígenas (Cfr. SCJN primera edición 2013 segunda edición 2014). De igual forma, la propia SCJN promovió un curso en línea sobre esta reforma, en cuyos materiales se plantea que la reforma constitucional del artículo $1^{\circ}$ en el 2011 hace referencia expresa al sentido y concepto de bloque de constitucionalidad (Rodríguez et al., 2013).

El bloque de constitucionalidad implica la existencia de un orden normativo constitucional que está en relación inescindible con el Derecho internacional de los derechos humanos y que se orienta a la protección efectiva de los derechos de todas las personas.

Pero dicho bloque no fue aceptado y dominó la postura conservadora de señalar a la Constitución y por tanto la interpretación que la SCJN haga, como límite de aplicación de los tratados internacionales de Derechos Humanos (ver SCJN Sesiones de la Suprema Corte. Intervención de la ministra Margarita Beatriz Luna Ramos, como representación del ala conservadora del organismo). Esto es muestra fiel de las tensiones por las que pasa el Estado mexicano $\mathrm{y}$, concretamente, su sistema jurídico (incluyendo a los organismos y dependencias encargadas de mantenerlo incólume) para hacer eficaz los derechos, sobre todo los que tienen que ver con el ejercicio autonómico para indígenas y no indígenas, excluidos o expulsados, en términos de Santos (1995 y 1998).

En resumen, la interpretación de la Corte mexicana sobre la aplicación de los tratados internacionales expone el temor que tiene una parte de los miembros de la SCJN (como parte del establishment) de que este organismo deje de ser el máximo órgano regulador del control constitucional. Pero también expresa el temor de esa clase política hacia los grupos sociales subalternos (Mallon 2003: 32) y emergentes, que han expresado su oposición a los megaproyectos en sus territorios, de que utilicen masivamente el Sistema Internacional de Derechos Humanos, no tanto para socavar, pero sí para cuestionar, con su propio discurso y sistema legal, el poder del Estado en su propósito de imponer el modelo económico neoliberal (Cruz y Santana, 2013; SCJN, 2013 en el caso Yaqui).

\section{La aplicación e interpretación de la norma: entre el pluralismo o la hegemonía del campo jurídico}

Los casos que abordamos muestran cómo los indígenas, sus comunidades y pueblos, lejos de aislarse o separarse del Estado y de la sociedad mexicana, buscan por todos los caminos que sus derechos (jurídicamente reconocidos) sean de facto, efectivos, y cuyo fin último es el cambio 
en la correlación de fuerzas, ganando más espacios en el ejercicio de sus derechos, autónomos o semiautónomos.

\section{Método de análisis}

Para nuestro análisis revisamos documentos que forman parte de los archivos de las comunidades a las que nos referimos. En el caso de Venustiano Carranza, tenemos un trato más cercano porque desde 2012 le damos apoyo al núcleo agrario, en la regularización en la elección de sus representantes y para la resolución de un conflicto agrario con varias aristas -conflicto de límites, invasión de tierras, suspensión de derechos a comuneros que han atentado contra la comunidad) que involucra el ejercicio de poder de un cacique local, que por medio de prestanombres se ha hecho de tierras de las comunidades agrarias colindantes y desde estas posesiones alienta la invasión de tierras de los bienes comunales de Venustiano Carranza.

Tuvimos acceso a los documentos de San Andrés Cohamiata, Jalisco y de Taniperlas, Chiapas, mediante organismos de derechos humanos y abogados con los que hemos coincidido en la defensa de los derechos de indígenas y sus pueblos.

Es importante subrayar que solo en el caso de Taniperlas se invocó el protocolo de actuación de la SCJN por sugerencia nuestra y en los de Carranza y San Andrés Cohamiata no. En el de Carranza no, porque cuando se da la separación de los comuneros dicho protocolo todavía no había sido publicado. En el caso de San Andrés Cohamiata, ignoramos por qué no invocaron el protocolo de la SCJN.

En este contexto tenemos que los casos a los que nos referimos, además de los puntos en común señalados, son núcleos agrarios con la facultad (reconocida dentro del derecho positivo mexicano) de reglamentar su vida interna. Esta capacidad se encuentra en el marco jurídico mexicano -que incluye la aplicación de los tratados internacionales sobre Derechos Humanos (artículo $1^{\circ}$ CPEUM), los Derechos de los Pueblos Indígenas (artículo $2^{\circ}$ CPEUM)-.

Nos referimos a tres comunidades que se autoadscriben como indígenas: San Andrés Cohamiata, en el estado de Jalisco, Venustiano Carranza y Taniperlas, en el estado de Chiapas. Las tres tienen tierras bajo la modalidad de propiedad social (de acuerdo con el artículo 27 de la CPEUM): las dos primeras comunidades son núcleos agrarios, cuya tenencia de la tierra está bajo el régimen de bienes comunales, y la tercera, bajo el régimen de ejido. Como parte de sus facultades está la elección de sus representantes agrarios y la de regular, por medio de estatutos comunales y reglamentos ejidales, entre otras, la aceptación o separación de comuneros y la delimitación de las tierras (artículo 23 de la Ley Agraria). Tal regulación se plasma en los llamados estatutos comunales y el reglamento interno que, dentro de la lógica jurídica positivista, serán válidos ante terceros, siempre y cuando pasen por el procedimiento de registro en el Registro Agrario Nacional (RAN).

Las funciones del RAN están establecidas en la CPEUM, Ley Agraria y en el Reglamento Interno del RAN. En estos instrumentos se establecen, en términos generales, las características de esta institución, así como los actos registrales que debe realizar, entre otros, mismos que tienen que ver con la tierra y, en general, los que señale la ley.

En este punto los funcionarios del RAN tienen que constatar que, en efecto, los actos que los sujetos agrarios pretenden registrar (y que podrán oponer o esgrimir frente a terceros) no contravengan la ley, entendida esta como toda norma comprendida en el marco jurídico mexicano. El RAN revisa que los actos cumplan las formalidades que señala la ley, por ejemplo, en el caso de asambleas de núcleos agrarios, que se cumplan los requisitos y formalidades para emitir las convocatorias, para llevar a cabo la asamblea de ejidatarios y comuneros (y que los que participaron en la asamblea, efectivamente sean ejidatarios o comuneros debidamente reconocidos) y en la elaboración del acta que resulta de esa asamblea.

\section{Entre los bienes comunales de los tsotsiles de Venustiano Carranza, municipio de su mismo nombre (Chiapas) y los wixaritari de San Andrés Cohamiata}

Estos casos muestran la manera cómo los indígenas, sus pueblos y comunidades, hacen un uso contestatario del Derecho, es decir, no solo invocan y usan la norma positivista dentro de las formalidades señaladas por el Estado, sino que generan espacios y procesos de discusión y argumentación frente a las autoridades que los representan, a lo que agregan mostrar representatividad y respaldo social con movilizaciones. Esto es una explicación preliminar de que los principios jurídicos positivistas 
de igualdad frente a la ley y de certeza jurídica no se aplican y que el pluralismo jurídico, como situación fenomenológica en la que se involucran procesos de uso de poder, genera procesos de aplicación diferenciada de una misma norma a sujetos aparentemente iguales.

$\mathrm{Al}$ analizar ambos casos, se detectó una posible contradicción jurídica de acuerdo con los propios términos y parámetros del derecho positivo mexicano, en el que quedan incluidos los órganos e instituciones encargadas de aplicarlo. Nos referimos, concretamente, a la aplicación de la normatividad respecto del reconocimiento de los derechos indígenas en México.

Los casos que se abordan de los bienes comunales de Venustiano Carranza, comunidad indígena tsotsil, y de la comunidad wixarita de San Andrés Cohamiata, municipio de Mezquitic (estado de Jalisco), quedan comprendidos dentro de la materia agraria o derecho agrario mexicano. En la primera comunidad se da la separación de comuneros y, en la segunda, la elección de los órganos de representación de los bienes comunales. En ambos casos los sujetos fundamentan sus actos tanto en la Ley Agraria (que es reglamentaria del artículo 27 de la CPEUM) como en los derechos indígenas internacionalmente reconocidos, concretamente el derecho a la autoadscripción al anteponer su identidad como pueblos indígenas, plasmado fundamentalmente en el Convenio 169 de la OIT y el artículo $2^{\circ}$ de la CPEUM.

En lo referente a la separación de comuneros, el proceso se establece en el artículo 23 fracción II de la Ley Agraria, que señala que es facultad de la asamblea general de los núcleos agrarios la aceptación y separación de ejidatarios y comuneros. Como lo apuntamos, en los casos que abordamos, nos referimos a comuneros por ser ambos bienes comunales.

El argumento de la separación de algunos comuneros de los bienes comunales de Venustiano Carranza es que estos ejercieron actos (que podrían constituirse en hechos delictivos sancionados por la legislación penal) contra la comunidad y sus miembros (intento de asesinato, robo en distintas modalidades y privación ilegal de la libertad. Ver acta de asamblea de 17 de febrero de 2013).

Es pertinente señalar que el proceso tiene sus antecedentes históricos y que, a diferencia de algunos procesos de "expulsión" que se han dado en la comunidad, en el caso que referimos, la asamblea general decidió hacerlo valer por la vía legal, haciendo uso del derecho que les confiere la Ley Agraria y dejando a salvo los derechos de los comuneros separados, para que aleguen lo que a su derecho les corresponda ante las instancias jurisdiccionales o administrativas. A la vez, se argumentó también todo lo concerniente a los derechos que establece el Convenio 169 de la OIT, específicamente en los artículos que se refieren al derecho a la aplicación de sus sistemas normativos para dirimir conflictos internos, siempre y cuando no se violenten derechos humanos. Con estos argumentos y usando el artículo $2^{\circ}$ de la CPEUM, donde se establece el derecho a la libre determinación de los pueblos indígenas, la asamblea general fundamenta la separación y su solicitud al RAN, para que el acta correspondiente donde se hace constar el acto de separación a esos comuneros, sea registrada para su plena validez (para ello, siguiendo las formalidades que la Ley Agraria señala para este supuesto, en segunda convocatoria se realiza asamblea y se verifica formalmente la separación).

Pese a cumplirse las formalidades que la Ley Agraria señala, al momento de llevar el Acta correspondiente para ser registrada ante el RAN, esta institución se tardó más de un año para emitir su dictamen de improcedencia, argumentando que la decisión de la asamblea violentaba los artículos 16 y 19 de la CPEUM. Ante esto, la comunidad decide interponer un recurso de inconformidad con base en el reglamento del RAN. En este recurso se señalaron las graves violaciones que comete la delegación Chiapas del RAN, ya que la comunidad se dedicó a indagar e investigar que, en otras latitudes de la República mexicana, o en otras delegaciones de la misma institución, sí han realizado registro de actos promovidos por las comunidades, los que a la luz del argumento del RAN en Chiapas no deberían ser Registrados. Este sería el caso de los bienes comunales de San Andrés Cohamiata, en el estado de Jalisco.

De esta manera, el RAN en Chiapas, en su negativa de registro del acta de separación de comuneros, señala que se violentan derechos de comuneros, excediéndose en sus funciones, pasando de facto de ser una instancia administrativa registral a ser una instancia de Defensoría de Oficio (tipo Defensoría Pública) a favor de los comuneros transgresores del orden interno, o incluso de impartición de justicia, ya que en todo caso corresponde a los tribunales agrarios decidir al respecto. 
Por lo anterior, los comuneros y representantes agrarios de Venustiano Carranza cuestionaron al RAN en Chiapas, ya que su postura sobrepasa lo señalado en el ordenamiento legal. En todo caso, y en ese escenario, les tocaría a los comuneros separados entablar una controversia en contra del RAN o de la asamblea general de comuneros, ante el Tribunal Agrario, para que expongan lo que a su derecho convenga, y no es facultad del RAN oponerse a que la ingeniería legal y jurisdiccional -llamada Estado de derecho- opere. Esto hace evidente el uso arbitrario de la norma jurídica, por parte de una institución del Estado mexicano, viendo en acción el fenómeno de diáspora jurídica de una norma general y abstracta.

En el caso de San Andrés Cohamiata, el 25 y 26 de enero de 2014, los pobladores llevaron a cabo su asamblea de cambio de órganos de representación, ante ello, un grupo de comuneros manifestó su inconformidad por presentarse varias irregularidades, fundamentalmente en lo concerniente a los requisitos que formalmente señala la ley para la elección y cambio de órganos de representación. Por ejemplo, argumentaron que en la asamblea no solo participaron comuneros sino también avecindados (todos integrantes del pueblo wixa). Es importante considerar que, en este tipo de actos, en el pueblo wixarita se presentan por tradición o usos y costumbres aproximadamente más de mil personas (de estas no todas son comuneros legalmente reconocidos) para realizar el cambio y elección de nuevos órganos de representación: el comisariado de bienes comunales y el Consejo de Vigilancia, por tanto, no cumplen las formalidades establecidas en la Ley Agraria. Esta cantidad de personas contrasta con el padrón "oficial de comuneros", que llega solo a 465 personas (apareciendo estas en la Resolución Presidencial o en la sentencia del Tribunal Agrario, según sea el caso), de estas el grupo o planilla que perdió muestra su inconformidad ante el RAN, el gobierno de Jalisco y la Procuraduría Agraria.

Pese a lo esgrimido por el grupo inconforme, a mediados de febrero de 2014 la delegación del RAN en Jalisco decide conceder el registro a la planilla ganadora, registrando el acta correspondiente y argumentando que con el acto registral del RAN en Jalisco se respetan los usos y costumbres de San Andrés Cohamiata, dejando a salvo los derechos de los inconformes.

Justamente, el argumento de respetar los usos y costumbres es el mismo que utiliza la Asamblea y el comisariado de bienes comunales de Venustiano Carranza. Sin embargo, ante la evidencia de la contradicción, encontramos que las delegaciones del RAN se comportan de una manera independiente y autónoma respecto de su función institucional, que se rige por el estado de derecho. Aquí es posible señalar que, para estas fechas, la decisión de la SCJN respecto de la NO aplicación del bloque de constitucionalidad ya se había dado.

Es en este contraste cuando podemos decir que se presenta el fenómeno de diáspora jurídica que muestra cómo la norma generada de manera centralizada en el seno del derecho mexicano, en contextos concretos y lejos de esa centralidad se muestra y opera para dar respuesta a casos específicos. Es decir, el criterio fundante por los que los actos de autoridad deben regirse ("nada ni nadie por encima de la Constitución" y "la ley es igual para todos"), al migrar a arenas políticas y espacios de justicia con presencia de diversidad cultural y política (sobre todo indígena), obliga a los funcionarios a aplicar, en el mejor de los casos a su criterio, y en el peor de los casos "a modo", los ordenamientos legales. De esta manera, los principios fundamentales de igualdad ante la ley y de seguridad jurídica se cumplen en unos casos, pero en otros no. Esto, dentro de la lógica jurídica monista positivista no es permisible, por lo que un acto de autoridad como el de la delegación del RAN de Jalisco contraviene esos principios de legalidad y seguridad jurídica. En todo caso, por el principio de igualdad ante la ley y el de propersona, tendría que aplicarse el beneficio que se dio a los wixaritari, de igual manera a los tsotsiles de Venustiano Carranza, como pueblo indígena con un derecho propio interno llamado usos y costumbres.

\section{Venta e ingesta de alcohol y enervantes como un} problema de salud (pública) comunitaria: El caso del Reglamento interno del ejido Taniperla, municipio de Ocosingo, Chiapas

En este caso encontramos que el ejido de Taniperla es una comunidad indígena perteneciente al pueblo tseltal, que cuenta con reglamento ejidal registrado en el RAN. En asamblea general de ejidatarios (en el 2013). En este caso el ejido decide modificar dicho documento para agregar un aspecto que se considera de trascendencia para la vida comunitaria, ya que afecta la integridad 
de las tierras ejidales y, por consiguiente, los derechos de hombres, mujeres, niños y niñas. Este aspecto se refiere a la venta e ingesta de alcohol y enervantes, asentándose los argumentos del precepto, aprobándose en el acta de asamblea y siendo los siguientes:

[...] En uso de la palabra, los ejidatarios y pobladores manifiestan su inconformidad ante la venta de las (sic) bebidas embriagantes y drogas, ante la violencia que viven las mujeres, niños y niñas, también porque ha provocado varios tipos de problemas en las familias, debido al consumo de las bebidas embriagantes o drogas, ya que no es la primera vez que ocurre, pero ahora lamentablemente terminó en desgracia, ya que una persona perdió la vida en la cárcel por su estado de embriaguez así como vemos que daña la unidad en el ejido, daña a las personas y daña a las familias.

Todas y cada una de las participaciones (sic) manifestaron y argumentan la necesidad de ratificar el acuerdo que ya existe en nuestro reglamento interno del ejido, establecido en el título segundo, capítulo segundo, artículo 9, apartado de obligaciones, inciso m) que a la letra dice: "se prohíbe la venta de bebidas embriagantes en el poblado del ejido" [el texto original está escrito en mayúsculas].

De esta manera, la asamblea ejidal aprueba la modificación del reglamento quedando el precepto a modificarse de la siguiente manera:

Titulo sexto. Sanciones. Artículo 79. A quien se sorprenda vendiendo alcohol o enervantes en el ejido taniperla, y a quien se sorprenda cometiendo violencia contra las mujeres o contra cualquier persona de la comunidad a causa del alcohol, serán puestos a disposición del agente rural, en caso de delitos contra la salud, delitos graves o reincidencias, se turnará a las autoridades competentes; o se pondrá (sic) en la asamblea ejidal, respetándose la sanción que la asamblea de ejidatarios y pobladores defina, tomando en cuenta el respeto a los derechos humanos [el texto original está escrito en mayúsculas].
El RAN, sin mayor justificación y en contra del artículo 16 de la CPEUM, niega el registro de las modificaciones al reglamento, señalando en el considerando segundo que "no es posible realizar la inscripción de la documentación presentada, debido a que el acuerdo tomado en la asamblea no es susceptible de inscripción en este órgano registral". Ante esto, el ejido decidió interponer recurso de inconformidad argumentando que el artículo $4^{\circ}$ del Reglamento Interior del RAN no señala nada al respecto. Sin embargo, vale agregar que, en efecto, el artículo $4^{\circ}$ de ese ordenamiento menciona:

La función registral, integración y actualización del Catastro Rural Nacional para llevar a cabo el control de la tenencia de la tierra, se llevará mediante las actividades que de calificación, inscripción, dictaminación y certificación de los actos y documentos en los que consten las operaciones relativas a la propiedad ejidal y comunal; a los terrenos nacionales y a los denunciados como baldíos; a las colonias agrícolas y ganaderas; a las sociedades rurales; y a las sociedades mercantiles o civiles propietarias de tierras agrícolas, ganaderas o forestales, así como los relacionados con la organización social y económica de los núcleos agrarios.

Es decir, en el criterio del funcionario registral, la venta e ingesta de alcohol no está directamente relacionada con el ejercicio de la tenencia de la tierra, las operaciones relativas a la propiedad ejidal y comunal y lo que tiene que ver con la organización social y económica de los núcleos agrarios, entendiendo esos actos de organización como los que justamente tengan que ver con la tierra.

Por ello el ejido, asesorado por Servicios de Asesoría para la Paz (SERAPAZ), decide agregar al aparato jurídico de su argumento ${ }^{4}$ el Convenio 169 de la OIT, el artículo $2^{\circ}$ y el segundo párrafo del artículo 27 de la CPEUM, así como el Protocolo de actuación para quienes imparten justicia en casos que involucren derechos de personas, comunidades y pueblos indígenas. Además, subraya el ejido en su argumento que en la introducción del protocolo se señala que este es una guía de actuación no solo para los juzgadores o autoridades jurisdiccionales, sino también para todas aquellas autoridades (jurisdiccionales y administrativas) que conozcan de 
casos en los que estén involucrados derechos de personas, comunidades y pueblos indígenas.

Y es así como en dicho protocolo se señala en el punto 4.4. Derecho al autogobierno:

El derecho a autogobernarse y elegir a sus autoridades usando sus propios procedimientos no implica que su ejercicio sea a través del municipio. Si bien este nivel de gobierno abre una posibilidad para ejercer este derecho, se tiene que admitir que un pueblo con libre determinación que puede definir sus formas de organización política interna con respeto a la CPEUM y a los derechos humanos, no puede quedar sujeto a instituciones políticas que le son ajenas. En este sentido podría pensarse que son formas de gobierno indígena las comunidades agrarias, las agencias o delegaciones municipales o las instituciones político-religiosas de sus comunidades e incluso se podría justificar la existencia de instituciones políticas supramunicipales si estas respetan los otros niveles de gobierno existente (SCJN 2014: 16).

De igual forma, el mismo protocolo de la SCJN señala en el punto 4.6. Derecho a aplicar sus propios sistemas normativos:

La CPEUM reconoce la existencia de sistemas normativos internos, aunque también los llama "usos y costumbres", los cuales resultan necesarios para definir la organización política, económica, jurídica, social y cultural interna, pero también para la resolución de sus conflictos internos y para la elección de sus propias autoridades como quedó de manifiesto en el caso Cherán (SCJN 2014: 16).

Finalmente, no está por demás señalar que los criterios que emite la SCJN en este protocolo de actuación, recogen la normatividad del Sistema Internacional de Derechos Humanos, que en materia indígena está encabezado por el Convenio 169 de la OIT y la Declaración sobre Derechos de los Pueblos Indígenas de la ONU.

Para reforzar su argumento, el ejido agregó que la ingesta de alcohol no solo altera el orden público, la seguridad y salud pública, y violenta los derechos de mujeres y niños, sino que, además, pone en riesgo la integridad de las tierras ejidales o las parcelas como parte del patrimonio de familia, ya que los ejidatarios, sobre todo hombres en estado de embriaguez, comprometen la parcela. Y dado que la legislación en materia civil es supletoria, este pedazo de tierra se considera patrimonio de familia.

Con lo anterior, los representantes del ejido se presentan ante el funcionario registral del RAN, quien, al leer el contenido del escrito, de inconformidad, decide no sellar de recibido y más bien les ofrece la posibilidad de emitir un Acuerdo de Prevención donde el funcionario registral anotó elementos de forma, que el ejido tenía que subsanar para inscribir el acta de asamblea donde se asentaba la modificación del reglamento interno, sin señalar mayor justificación o argumentación. Sobre todo, porque en el precepto que se propone modificar se puede apreciar que, si no se remite al Ministerio Público a los infractores, estos podrán ser llevados ante la asamblea, instancia que tendrá que resolver apegándose a los Derechos Humanos. Es decir, se observa la reivindicación de un sistema normativo interno o Derecho indígena, el que, sin duda, también forma parte del corpus conocido por los no indígenas como "usos y costumbres".

\section{Conclusión}

Partimos de que al interior del ordenamiento jurídico mexicano o Derecho positivo existen dos dimensiones, la de la norma escrita y la de su interpretación, que dan lugar a una norma no escrita y por tanto no reconocida por el Derecho mexicano. La existencia de estas dos dimensiones nos muestra que en vía de hecho o en la práctica, la resolución de la SCJN en el sentido de limitar la aplicación de los tratados internacionales a la letra de la Constitución queda como un criterio u opinión a tomarse en cuenta, pero no forzosamente por los operadores de justicia, sobre todo cuando estos no forman parte del aparato jurisdiccional del Estado, por tocarles el ámbito administrativo.

Casos como los expuestos en este trabajo se dan cotidianamente donde no coincide qué dice la norma, con la manera en cómo se interpreta y cómo se aplica (sobre todo en materia penal). Y que, en el trabajo de hacer justicia de los operadores y operadoras, jueces y juezas, al estar sensibilizados en cuestiones de diversidad en general y específicamente de diversidad cultural, en los casos concretos y frente 
a sujetos de carne y hueso, tienen que hacer uso de su criterio jurídico (y político), acuñado por su instrucción formal y experiencia. Ejemplo de esto son las entidades federativas de Oaxaca y Campeche, en donde el Tribunal Superior de Justicia de cada una de ellas aprobó la aplicación del protocolo de actuación de la SCJN. El protocolo de actuación para quienes imparten justicia en casos que involucren derechos de personas, comunidades y pueblos indígenas, da cuenta de que la diáspora jurídica más que un defecto es una puerta de oportunidad para lograr cambios en el sistema jurídico mexicano: la construcción de un Estado de derecho eficaz y eficiente, que realmente se aplique a todos y todas considerando la diversidad y el reconocimiento cabal de los Derechos Humanos.

En la historia de México y de la Justicia mexicana falta mucho por andar para que la diáspora que existe o se detona por acciones u ordenamientos externos al derecho mexicano, provoque un estado de cosas que obligue a la Corte mexicana a reconocer lo que de facto está sucediendo: la puesta en marcha desde los actores locales de un bloque de constitucionalidad.

\section{Referencias Citadas}

Adams Newbold, Richard

1978 La red de la expansión humana. Centro de Investigaciones Superiores del INAH. México.

Arcos García, María de los Ángeles

1998 Las velas tateikietari... invocando la lluvia y la lucha de un pueblo (Tesis de maestría en Desarrollo Rural). Universidad Autónoma Metropolitana Xochimilco. México. Bal, Mieke

2006 "Conceptos viajeros en las humanidades". Estudios Visuales. 3: 28-77.

Corcuera, Santiago

2016 Crisis de la Comisión Interamericana de Derechos Humanos en: http://www.eluniversal.com.mx/entradade-opinion/articulo/santiago-corcuera/nacion/2016/06/4/ crisis-de-la-comision-interamericana (consulta del 29 de junio de 2016).

Bourdieu Pierre

2011 Las estrategias de la reproducción social. Buenos Aires. Siglo Veintiuno Editores.

Cruz Rueda, Elisa

2014 Derecho indígena: dinámicas jurídicas, construcción del derecho y procesos de disputa. México, Instituto Nacional de Antropología e Historia (INAH), Consejo Nacional para la Cultura y las Artes (CONACULTA).

Cruz Rueda, Elisa y Elizondo Zenteno, María del Pilar

2016 "Ejercicio de gobierno indígena desde los Bienes Comunales de Venusttiano Carranza". En: UNA Revista de Derecho. Bogotá. Universidad de los Andes.

Cruz Rueda, Elisa y Ma. Eugenia Santana

2013 “¿Reconocimiento jurídico de la diversidad cultural sin ejercicio de derechos?". En: Revista Pueblos y Fronteras Digital, 16: 218-255, Universidad Nacional Autónoma de México. Programa de Investigaciones Multidisciplinarias sobre Mesoamérica y el Sureste. México.

Chenaut González-Lelong, María Victoria y Sierra Camacho, María Teresa

1995 Pueblos indígenas ante el derecho. México. Centro de Estudios Mexicanos y Centroamericanos (CEMCA) y Centro de Investigaciones y Estudios Superiores en Antropología Social (CIESAS).

Díaz de Salas, Marcelo

1995 San Bartolomé de los Llanos en la escritura de un etnógrafo. 1960-1961. Diario de Campo. Venustiano Carranza,
Chiapas. Tuxtla Gutiérrez, Gobierno del Estado de Chiapas y Universidad de Ciencias y Artes del Estado de Chiapas.

Escalante Carbajal, Kevin

2010 La construcción de la territorialidad y la identidad en los procesos rituales, la cosmovisión y la organización social: La comunidad de San Sebastián Teponahuaxtlán, una comunidad wixarika. Tesis de licenciatura. Universidad Autónoma de San Luis Potosí.

González Esponda, Juan

1989 Movimiento campesino chiapaneco 1974-1984. Tesis de Licenciatura en Economía. Área de Ciencias Sociales. Universidad Autónoma de Chiapas. Campus III. San Cristóbal de Las Casas, Chiapas.

González Galván, Jorge A.

1995 El Estado y las etnias nacionales en México: la relación entre el derecho estatal y el derecho consuetudinario. México, Universidad Nacional Autónoma de México.

Gutiérrez, Alicia B.

2011 "Clases, espacio social y estrategias. Una introducción al análisis de la reproducción social en Bourdieu". En: Bourdieu Pierre (2011) Las estrategias de la reproducción social. Buenos Aires. Siglo Veintiuno Editores.

Liffman, Paul

2012 La territorialidad Wixarika y el espacio nacional. Reivindicación indígena en el Occidente de México, Zamora, Michoacán. El Colegio de Michoacán, A.C. Centro de Investigaciones y Estudios Superiores en Antropología Social.

Mallon, Florencia E.

2003 Campesino y nación. La construcción de México y Perú poscoloniales. México. El Colegio de San Luis, Colegio de Michoacan, Centro de Investigaciones y Estudios Superiores en Antropología Social.

Moreno, Orquídea

2014 "Cacaluche: ruedas florales. Uso y manejo de la flora para el ceremonial", Horal. Edición especial, diciembre 2014: 14-20, Chiapas.

Orantes García, José Rubén

2014 Derecho Tenejapaneco, Procedimientos Legales Híbridos Entre Los Tseltales de Chiapas. México. Universidad Nacional Autónoma de México. Programa de Investigaciones Multidisciplinarias sobre Mesoamérica y el Sureste. México. 
Orantes García, José Rubén

2007 Derecho Pedrano: estrategias jurídicas en los altos de Chiapas. Volumen 14 de Científica. Universidad Nacional Autónoma de México. Programa de Investigaciones Multidisciplinarias sobre Mesoamérica y el Sureste. México.

Renard, María Cristina

1998 Los llanos en llamas: San Bartolomé, Chiapas. Universidad Autónoma de Chapingo. México.

Rodríguez Manzo, Graciela, Juan Carlos Arjona Estévez y

Zamir Fajardo Morales

2013 Reforma DH Bloque de Constitucionalidad. Metodología para la enseñanza de la reforma constitucional en materia de derechos humanos. México, Comisión de Derechos Humanos del Distrito Federal, Suprema Corte de Justicia de la Nación, Organización de Naciones Unidas, Oficina en México del Alto Comisionado de Derechos Humanos.

Sieder, Rachel y María Teresa Sierra

2011 "Acceso a la justicia para las mujeres indígenas en América Latina," CMI working paper, Chr. Michelsen Institute, Bergen. En: http://www.rachelsieder.com/ wp-content/uploads/2015/01/Acceso-a-la-justicia-para-lasmujeres-indígenas-en-América-Latina.pdf (consulta del 07 de Mayo de 2019 Disponible)

Sierra Camacho, María Teresa

2002 "Derecho indígena: herencias, construcciones y rupturas". En: Guillermo de la Peña y Luis Vásquez León (coords.), La antropología sociocultural en el México del milenio. Búsquedas, encuentros y transiciones. México. Instituto Nacional Indigenista (INI), Consejo Nacional para la Cultura y las Artes (CONACULTA) y Fondo de Cultura Económica (FCE).

Santos, Boaventura de Sousa

1991 Estado, Derecho y Luchas Sociales. Bogotá, Instituto Latinoamericano de Servicios Legales Alternativos.
Santos, Boaventura de Sousa

1995 Toward a New Common Sense: Law, Science and Politics in the Paradigmatic Transition. Nueva Cork-Londres, Routledge.

Santos, Boaventura de Sousa

1998 La globalización del derecho: los nuevos caminos de la regulación y la emancipación. Bogotá, ILSA-Universidad Nacional de Colombia.

Stavenhagen, Rodolfo, coord.

1982 Derecho indígena y derechos humanos. México, Colegio de México.

Suprema Corte de Justicia de la Nación

2014 Protocolo de actuación para quienes imparten justicia en casos que involucren derechos de personas, comunidades y pueblos indígenas. México, Suprema Corte de Justicia de la Nación.

Suprema Corte de Justicia de la Nación

2013 Videoteca de Sesiones, en http://www.sitios.scjn.gob. $\mathrm{mx} / \mathrm{video} /$ ?q=category/expediente/2932011 (consulta del 13 de octubre de 2013).

Téllez Lozano, Víctor Manuel

2014 "Acercamiento al estudio de los sistemas de cargos entre las comunidades huicholas de Jalisco y Nayarit, México". En: Diálogo Andino, 43:17-40, Universidad de Tarapacá, Arica, Chile.

Mallon, Florencia

2003 Campesino y nación. La construcción de México y Perú poscoloniales, México: El Colegio de San Luis-El Colegio de Michoacán-Centro de Investigaciones y Estudios Superiores en Antropología Social.

Valladares de la Cruz, Laura, Maya Lorena Pérez Ruiz y Margarita Zárate (coords.)

2009 Estados plurales. Los retos de la diversidad y la diferencia. México, UAM-I, Juan Pablos.

\section{Notas}

1 El trabajo se enmarca en la línea de investigación: Autogestión, Derechos y Políticas Públicas, que se viene desarrollando desde hace más de diez años. Por lo mismo, es el resultado del acompañamiento a actores locales: ejidos, comunidades y pueblos indígenas, sus representantes y autoridades. Los materiales que se usan del Registro Agrario Nacional fueron proporcionados directamente por esos actores, ya que parte del acompañamiento consiste en darles asesoría jurídica para la invocación y defensa de sus derechos.

2 En mayo de 2015 tuve la visita de Honorio Mendía Soto, abogado O'dam (pueblo originario ubicado en el centro norte de la República mexicana) quien cursa la Maestría de Antropología Jurídica en la Facultad de Filosofía de la Universidad Autónoma de Querétaro. En su estancia académica conmigo compartimos reflexiones acerca del Derecho indígena más allá de sus diálogos y oposiciones con el Derecho positivo mexicano, y pudimos constatar similitudes entre ordenamientos indígenas, como lo es este elemento.

3 Acuerdos de San Andrés 1996. En la parte de pronunciamiento conjunto el Estado mexicano por medio del gobierno federal y del gobierno del estado de Chiapas reconocen que la relación del Estado mexicano y la sociedad mexicana han sido marcados por la pobreza, explotación y exclusión política; la homogeneización y asimilación cultural.

4 En este caso, recibí solicitud de compañeros de SERAPAZ para revisar su recurso, ante ello yo sugerí la ampliación de la argumentación que se expone. 